American Journal of Law and Legal Studies
(ISSN:2638-2202)

\title{
Serial Killers - Views on Why Sadipaths Kill, the Death Penalty, and Rehabilitation
}

\author{
Raqota Berger \\ Center for Criminal and Psychological Studies, Los Angeles, California
}

\begin{abstract}
Serial killers are among the most brutal, callous, and coldhearted criminal offenders. This is particularly true for sadipathic killers, that have no remorse for their acts and no empathy for their victims. This study analyzed statistical data collected from 220 people willing to share their thoughts and beliefs about serial murderers, why they repeatedly kill, whether they can be effectively treated and rehabilitated, and whether or not they should receive the death penalty. The findings revealed that most respondents believe that serial murder is connected to mental illness (82\%), childhood abuse (81\%), sadistic personality $(75 \%)$, and anger (69\%). The majority of respondents do not believe that serial killers can be treated or rehabilitated $(79 \%)$. The majority of the participants also stated that serial killers should receive the death penalty $(62 \%)$. Almost 8 out 10 respondents believe that serial murder is associated with a sadistic personality. Respondents 40 years of age and older (90\%) were palpably more likely to believe that serial killers should receive the death penalty. With the exception of multiracial respondents, all ethnic groups leaned in the direction that serial killers should receive the death penalty. This study brings forth additional findings and insights into serial murder and sadipathy that may be of value to professionals working across academic, mental health, and legal settings.
\end{abstract}

Keywords: serial murder, serial killer, sadipathy, death penalty, rehabilitation, mental illness

\section{*Correspondence to Author:} Raqota Berger

Center for Criminal and Psychological Studies, Los Angeles, California

How to cite this article:

Raqota Berger.Serial Killers Views on Why Sadipaths Kill, the Death Penalty, and Rehabilitation. American Journal of Law and Legal Studies, 2020, 3:6

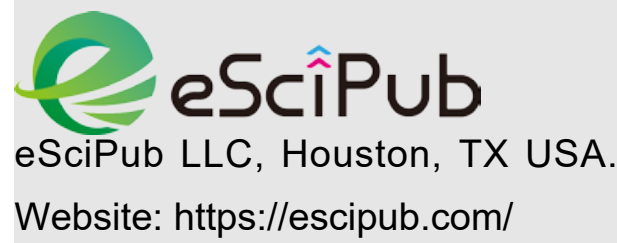




\section{Introduction to the Subject}

Experts across various academic disciplines and applied professions have long tried to make sense of what motivates and causes some people to repeatedly kill others. Forensic and criminal psychologists often study serial murder from behavioral, cognitive, and psychological standpoints. They like to try and make sense of the mental health and functioning of these types of offenders, what their backgrounds were like, and why they are driven to commit their heinous acts. Law enforcement experts examine psychological and behavioral factors as well, but they are largely interested in profiling serial killers to increase their chances of capturing these offenders and preventing future victimizations. At this time, there is no agreed upon etiology for serial murder. There are many complex genetic-biological, psychological, cognitive, familial, social, and environmental interactions at play that can cause one to go down this dark and vicious path. No single interaction has yet to be identified; or even can be identified, as there is not a single explanation or interplay at work. It appears that each complex interaction has its own cognitivebehavioral effect on each particular offender (James, 2019; LaBrode, 2007; Miller, 2014).

Serial killers are unique in their categorization as being murderers due to the fact that they kill on more than one occasion. Although there is some variation as to how many times one must kill to be labeled a serial killer (e.g., 2 to 4), it is generally accepted that 3 or more separate acts meets the criteria (Bartels \& Parson, 2009; Haggerty, 2009; James, 2019). The primary interest really comes down to why they kill in the first place. What drives them? What motivates them to inflict pain and injury on others? Why are they so callous toward their victims? Can they be treated and rehabilitated? Should they receive the death penalty for their actions? These are questions and concerns that academics and applied professionals should take into consideration as they conduct their duties and disseminate their findings. It is critical to best understand the complex reasons and motivations as to why sadipathic serial killers commit the horrific acts that they do. The current study on this topic brings forth additional information and findings that may be useful for those working in this area and that would like to gain more insight into what the public thinks about this particular offending population.

\section{Appurtenant Literature Review}

There are currently no established theories or etiological descriptions that can adequately explain or capture the commencement of a serial killer's horrific and deadly actions (Lynes \& Wilson, 2015; O'Toole, 2018). A number of traits and factors have been attached to practically all serial killers that brutally injure and murder their victims. It is widely accepted that serial killers are generally manipulative, narcissistic, lacking in empathy, callous, cold-blooded, guiltless, lacking in social conscience, exploitative, excitement-seeking, and purposeful (Anderson \& Marcus, 2019; Fox \& DeLisi, 2019; Garcia \& Moraga, 2017). Reidy, Zeichner, and Seibert (2011) studied sadistic aggression and found that these types of criminal offenders are typically emotionally detached from their victims, have affective shallowness, lack remorse, are impulsive, and are prone to boredom. The researchers also found that sadistic offenders are commonly low in socialization, are often irresponsible, show superficial charm, and often abuse substances. This is in line with what Spehr, Hill, Habermann, Briken, and Berner (2010) found in their research on sexual murderers, whereby it was determined that sexual homicide is closely associated with drug and alcohol dependency, prior violent sexual behaviors, and a high prevalence of antisocial personality disorder.

Although antisocial personality disorder and sociopathy are often connected to violent acts, most of these types are not murderers. Antisocial personalities often engage in purposeful violence, have poor behavioral controls, are conning, egocentric, and have hostile internal working models (LaBrode, 2007; 
Miller, 2004). Serial killers seem to be operating from a somewhat different internal model and frame of mind. According to Lachmann \& Lachmann (2007), serial killers have a strong need for self-assertion and control over others. They often come from backgrounds of early abuse, deprivation, and deception (although this is not always the case). The researchers noted that in addition to their common charm, manipulativeness, and sociability, most serial killers clearly have a distorted set of motivations and a specific fantasy system that leads to their violent compulsions. Anderson and Marcus (2019) noted that through their antagonistic personalities and interpersonal detachment, sadistic offenders derive pleasure from harming others. The sadist does not experience guilt or feelings of empathy that a normal person would and they revel in their coldhearted and excessively cruel behaviors (March, 2019). The enjoyment that sadists take in humiliating and hurting others is at the heart of sadipathy.

Sadipaths are among the most extreme and wicked offenders. Sadipathic offenders lack internal controls, are callously egocentric, and have a very cold indifference toward their victims. Sadipathic killers are void of empathy toward those that they victimize. They take extreme warped pleasure in denigrating their victims and causing them to suffer both psychologically and physically (Berger, 2019). Sadistic offenders often take sexual pleasure in their acts, which is why sexual assault and rape are so common with this particular offending population (Miller, 2014; Reidy, Zeichner, \& Seibert, 2011). It is argued that sadipathic serial killers lack deterrence and internal controls that act on most people in the population. Harmening (2014) explained that serial killers generally have attachment issues and lack moral development. This is what makes it so easy for them to gain the trust of their victims and to manipulate and harm them (e.g., Ted Bundy). In their research with 100 male sex offenders, Mokros, Osterheider, Hucker, \& Nitschke (2010) it was found that half of the offending group were clinically sadistic. A two-factorial solution design produced results that demonstrated that sexual sadism was a distinct pathology that consisted of aggressive sexual fantasies, emotional detachment, a readiness to harm, coercion, and a drive to inflict suffering on others. Similar findings were produced from the work of HaggarJohnson and Egan (2010) where it was shown that those with sadistic personality pathologies were prone to interpersonal cruelty, dominating others, intimidation, detachment, and vindictiveness. The findings of the research also found that these sadistic types were also low in agreeableness, are cold-blooded, are controlling, and are typically antagonistic.

Sadipathic killers are understood to be the most violent and cruel of all offenders. Examples of these types of offenders would include Samuel Little, Aileen Wuornos, Jeffrey Dahmer, Ted Bundy, John Gacy, Dennis Rader, and Joseph DeAngelo. Samuel Little is now believed to be the most prolific serial killer in American history. At this time, it has already been confirmed that he has killed over 50 women, and it is generally believed that he may have killed closer to 100 during his 35-year reign of terror (Holcombe, 2019; Palazzolo, 2019). Little has become the quintessential example of a sadipathic killer. During his premeditated attacks against vulnerable women, he would typically beat and strangle his victims to death. His attacks were cold-blooded, cruel, and violent. He displayed no remorse, shame, or empathy for his brutalized victims. His reign of terror did not stop because of his conscience or newfound morality, it was because of his age and declining opportunities (Berger, 2019; Janos, 2018).

Aileen Wuornos is an example of another sadipathic murderer. Wuornos was executed in Florida in 2002 for the murder of 7 men. In line with the position that sadipathic killers come from dysfunctional backgrounds, Wuornos suffered physical and sexual abuse in childhood and became engaged in sex work when she was still a minor. According to Arrigo and Griffin (2004), Wuornos became a predatory, 
calculated, and cold-blooded murderer after developing a hostile internal working model related to maladaptive patterns of unhealthy bonding and attachment. Her emerging personality style and disposition was defined by egocentrism, remorselessness, conning, cheating, lying, lack of empathy, impulsivity, glibness, and violence. Her sense of emotional detachment, extreme narcissism, need to render others powerless, and predatory violent nature, all place her firmly within the typology of the sadipathic offender (Arrigo \& Griffin, 2004; Berger, 2019; Miller, 2004). Another serial killer that fits perfectly into this typology includes Ted Bundy, that violently murdered somewhere between 30 to 100 women. Bundy was cold and calculated in his attacks, showed no remorse or empathy, and frequently used manipulation in his efforts. John Gacy is known to have killed 33 young males and to bury most of them under his house (until there was no more room for the bodies). He was also known as a conning and manipulative killer that had no regard for the lives and suffering of his victims (James, 2019).

Jeffrey Dahmer is another example of a sadipathic serial killer. Dahmer is known to have drugged and killed 17 young males, after which he often dismembered their bodies, ate body parts, and engaged in necrophilia (James, 2019). Dahmer had a sadistic etiology comprised of a distorted reality whereby he developed sadistic fantasies, an extreme need to diminish tension, feelings of being unloved, and rage (Martens, 2011). The researcher also conceived of a psychodynamic connection between the thinking and behaviors of Dahmer to his extreme feelings of deep loneliness, frustration, and a quite disturbing oral-sadistic development (Martens, 2011). Dahmer's lack of guilt, empathy, and extremely grotesque actions fit him directly in with the category of a sadipathic serial killer. Dennis Rader is another example of the prototypical sadipathic offender that employed "hit kits" when he went out to attack, butcher, and kill his victims. His reign of terror spanned over a 30-year period. Rader displayed all of the traits and behaviors of the sadipath, including viciously injuring and humiliating his victims, premeditation and planning, lack of remorse, and a clear lack of empathy for those that he attacked (Bartels \& Parsons, 2009). Rader was sexually motivated, as are most sadipathic offenders, and became aroused over his control and power over his victims. He targeted women that were vulnerable and powerless (e.g., sex workers) and he liked to tie the women up, place bags over their heads, and then strangle and suffocate them (Bartels \& Parson, 2009; Berger, 2019; Lynes \& Wilson, 2015).

Joseph DeAngelo, also known as the Golden State Killer, or the East Area Rapist, was captured and charged in 2018 for multiple rapes and murders. It is believed that DeAngelo killed at least 12 people, raped over 50 women, and committed hundreds of property crimes. DeLisi (2018) proposed that sexual homicide is often driven by impulse and intoxication; much of the time by those that live transient lifestyles and are repeat offenders. According to Sabalow (2018), DeAngelo liked to tie up, rape, and taunt his victims. He was even known for calling some victims after the attacks to further threaten and terrorize them. He even toyed with and taunted family members (children and husbands) while he was sexually assaulting the women. DeAngelo's spree of terrorism lasted from his 20 's into his 40's. DeAngelo was a prolific, sadistic, purposeful, callous, and well-planned predatory killer (O'Toole, 2018).

Some cold-blooded serial killers also work in areas where one may least expect it. For example, between the years of 1970 and 2010 there have been 58 healthcare workers identified that have engaged in serial killing (Lubaszka, Shon, \& Hinch, 2014). The researchers found that these killers, that are usually female, are often "organized" in their endeavors and target vulnerable victims, such as patients under their care. Examples of this would include nurses that give lethal injections to those that they have built trust with. The 
motives for these healthcare serial killers include godlike control over their victims, power, and paraphilic sexual arousal. These perpetrators also exhibit the core characteristic features of sadipaths regarding manipulation, narcissism, control, lack of distress over their actions, and lack of guilt (Lubaszka, Shon, \& Hinch, 2014; Ramsland, 2007). Castle and Hensley (2002) examined serial killers in military culture and found that the very culture of the military can cause some to engage in homicide. Through the perspective of social learning theory, it was proposed that military members learn to internalize an aggressive and violent mentality, which can lead to subsequent acts of unjustified murder. Again, it can be seen how much of this is also connected to environmental, interpersonal, and sociological variables (Castle \& Hensley, 2002; LaBrode, 2007; Miller, 2014).

The study and etiology of serial murder is a complicated matter. Research in this area tends to be more exploratory than explanatory, and it is extremely difficult to formulate any verifiable theories or quantifiable explanations (Castle \& Hensley, 2002; Martens, 2011; O'Toole, 2018). Controlled experimentation and clinical trials are obviously not ethically or legally possible, so research is really limited to after-the-fact interviews, case histories, and research that studies relevant concepts and theories in a more indirect and inferential manner (James, 2019; March 2019; Mokros et al., 2010). What is well understood is that serial killing needs to be studied and analyzed through a lens consisting of psychological, genetic, neurological, behavioral, cognitive, interpersonal, and environmental components (Fox \& DeLisi, 2019; LaBrode, 2007; O'Toole, 2018; Spehr et. al., 2010). By studying the phenomenon of serial murder from various perspectives and approaches, academics and applied professionals will be better informed and situated to diligently work to reduce and prevent these types of extreme criminal acts. This study will bring forth additional insight and information to add to the attested base of knowledge on this culturally relevant topic.

\section{Methodology}

\section{Design}

This study collected data via a quantitative questionnaire designed to gather both demographic information and information on the respondent's thoughts and beliefs about serial killers. Questions on the survey asked the respondents about their thoughts on why serial killers murder people, whether or not serial killers can be successfully treated and rehabilitated, and whether they should receive the death penalty for their actions. Other items on the questionnaire collected information on their beliefs about how many people need to be killed before one can be labeled a serial killer, what the average age of a serial killer is, and whether or not serial killing is connected to a sadistic personality. Data for the study was collected at all four levels of measurement. Demographic information was collected at the nominal and ordinal levels to allow for meaningful group comparisons (e.g., social class, ethnic identity, gender). Interval and ratio level data were also collected to allow for certain parametric analyses.

The central intention of the study was to capture people's thoughts and views about serial killers and why they commit their brutal acts. The questionnaire was able to be completed in less than five minutes. To be eligible to participate in the study the respondents needed to be at least 18 years of age. Consent to participate in the study was given by the respondent's willingness to fill out the survey. No deception was used in this study. Respondents were informed about the nature and purpose of the study. If the participants had any questions about the study these were answered honestly and in detail to help ensure that they were fully informed about the nature and purpose of the study. There was no compensation provided for participating in the study. All questionnaires included in the final sample and analysis appeared to have been 
completed in an effortful and honest manner by the study participants.

\section{Final Sample}

The final sample count for this study was 220 . Study participants were recruited using nonprobabilistic sampling methods from various locations across Southern California, including local businesses, homes, shopping malls, and college campuses. Some questionnaires were also filled out through telephone interviews, online, and via social media. No minors were included in the study. The age range of the participants spanned from 18 to 75 . The largest percentage of respondents were between 18 and 29 years of age $(n=149,67.7 \%)$. The remaining age cohorts broke down as, those in their 30's ( $n=42,19.1 \%), 40$ 's ( $n=12,5.5 \%)$, 50 's $(n=14,6.4 \%), 60$ 's $(n=1,0.5 \%)$, and 70 's $(n=2,0.9 \%)$. Women made up the bulk of the final sample $(n=141,64.1 \%)$. Men made up $33.6 \%$ of the final sample $(n=74)$. Two of the respondents identified as "other" and three respondents did not answer this particular question. Most of the sample consisted of those identifying with the working class $(n=131$, $59.5 \%$ ). Middle class respondents made up $28.6 \%$ of the final sample $(n=63)$. Nineteen of the respondents $(8.6 \%)$ were from the lower class, and one $(0.5 \%)$ identified with the upper class. Six participants $(2.7 \%)$ did not answer this particular question.

Hispanic respondents made up the bulk of the sample $(n=145,65.9 \%)$. This is generally in proportion with the population characteristics of Southern California. White respondents made up $15.9 \%$ of the sample $(n=35)$. There were also 14 Asian respondents (6.4\%), 11 Black respondents $(5.0 \%), 5$ Middle Eastern respondents $(2.3 \%), 6$ Multiracial respondents $(2.7 \%)$, and 1 Native American respondent $(0.5 \%)$. Three of the study participants did not answer this particular question (1.4\%). Due to small sample sizes across certain demographic groups (e.g., Native American, upper class, those over 60 years of age) it was not possible to conduct certain statistical analyses. In some instances it was necessary to remove specific groups from the analyses and interpretations to stay within the requirements of particular statistical tests.

\section{Procedure and Examination of Data}

All data were statistically examined through the use of the SPSS software program. Descriptive and inferential statistics were analyzed across both categorical and continuous level data. Measures of spread and central tendency were utilized to help make sense of group differences and any notable patterns across the sample. Parametric and nonparametric tests and measures were run and analyzed to assist with a more thorough investigation of the presenting data (e.g., chi-square, binomial, phi, Cramer's V, $t$-test). All inferential tests of significance were set at the conventional 0.05 level of probability. Any analysis that resulted in a probability level that exceeded 0.05 was deemed to be statistically insignificant and treated as such. Only analyses that have met the standard probability level have been explicated further in this final report. All inferential tests were twotailed for the purposes of this study. All of the surveys included in the final examination were filled out in a clear manner and purposeful manner. With this, it believed that the ensuing findings and discoveries are both valid and useful. The subsequent section of this report will bring forth additional information and analytic apprehension regarding the thoughts and views that people have about serial killers, their reasons for killing, the death penalty, treatment and rehabilitation, and categorizing.

\section{Findings of the Study}

Each participant in the study was asked a number of questions about what they believe best helps to explain why serial killers murder people. Out of the 219 research participants that answered this question, 109 (.50) believe that substance abuse and addiction are connected to serial murder. A binomial test indicated that this proportion was exactly what was expected (test $p=.50)$ in regard to how people feel about substance abuse and addiction. Along the same 
lines, and where all test probabilities were set at $.50,180(.82)$ believe that mental illness helps to explain serial murder. A binomial test indicated that this was not what was expected and that people are more likely to believe this than expected by chance $(p=.000)$. Only $26(.12)$ of the respondents believe that serial murder is connected to low intelligence. This was significantly lower than what would be expected by chance $(p=.000)$. Seventy-one (.32) of the respondents believe that jealousy plays a role in serial murder. This was significantly lower than what would be expected by chance $(p=.000)$. The bulk of participants believe that anger is associated with serial murder $(n=152, .69)$. This is significantly higher that what would be expected by chance $(p=.000)$. When asked if they believe that sadistic tendencies were associated with serial murder, 133 (.61) said that is was. This is higher than what would be expected $(\mathrm{p}=.002)$. Only $69(.31)$ of the respondents believe that fame and media attention are connected to serial murder. This is lower than what would be expected at a test probability of $.50(\mathrm{p}=.000)$.

Seventy-five (.34) of the participants felt that the need to degrade and humiliate others is associated with serial murder. This was lower than what would be expected $(p=.000)$. Ninetysix (.44) of the participants believe that sexual satisfaction is linked to a serial killer's behavior. This did not deviate from what was expected $(p$ $=.079$ ). When asked if they believed that coming from an abusive childhood is associated with serial murder, $177(.81)$ stated that it did. This was significantly higher than what would be expected by chance $(p=.000)$. Eighty-six (.39) of the respondents believe that serial murder was connected to deficient parenting. This was lower than what would be expected by chance ( $p$ $=.002$ ). Out of all of the reasons indicated by the study respondents, it appears that mental illness, childhood abuse, anger, and sadistic tendencies are cognitively the most closely associated with serial murder.

When analyzing group differences between social classes and their thoughts on substance abuse and addiction, a one-way chi-square test revealed a significant finding, $x^{2}(3, N=213)=$ $11.32, p=.010$. Middle class respondents $(61.9 \%)$ were significantly more likely to feel that serial murder is associated to substance abuse and addiction than respondents from both the working class (46.9\%) and lower class (21.1\%). Symmetric measures of association were produced to highlight any notable cognitive associations that the respondents have in regard to which factors help to best explain why serial killers commit their brutal acts. Table 1 highlights these significant findings. As can be seen, several factors appear to stand out, such as sadistic tendencies, anger, substance abuse/addiction, and abusive childhoods. Sadistic tendencies and anger appear to be the two most compelling across the symmetric measures.

Table 1. Associated Factors and Serial Killing

\begin{tabular}{lccc}
\hline & \multicolumn{1}{c}{ Value } & & \multicolumn{1}{c}{ Significance } \\
Substance abuse/addiction x Mental illness & .153 & \\
Substance abuse/addiction x Anger & .324 & .024 \\
Anger x Jealousy & .375 & .000 \\
Anger x Sadistic tendencies & .386 & .000 \\
Sadistic tendencies x Sexual satisfaction & .334 & .000 \\
Sadistic tendencies x Need to degrade/humiliate & .324 & .000 \\
Sadistic tendencies x Abusive childhood & .178 & .000 \\
Poor parenting x Abusive childhood & .344 & .008 \\
\end{tabular}


When respondents were asked what they believe the average age of a serial killer is, the responses ranged from 13 to 48 . The average age across the sample was $30.1(\mathrm{SD}=6.67)$. An independent samples $t$-test produced a significant finding in regard to Hispanic and White respondents and their beliefs about the average age of serial killers, $t(168)=-3.21, p=$ .002 . White respondents appear to believe that serial killers are older $(33.3, S D=6.48)$ than Hispanic respondents $(29.14, \mathrm{SD}=6.82)$. An additional $t$-test looking at the social class of respondents and their beliefs concerning the average age of serial killers also produced a significant finding, $t(76)=-2.15, \mathrm{p}=.035$. Respondents from the middle class feel that serial killers are older $(31.0, S D=6.59)$ than those from the lower class $(26.9, S D=6.98)$. When asked how many people need to be killed before one can be labelled a serial killer, the average number across the sample was 3.17 $(S D=1.78)$. This is in line with the criterion established by the nation's leading law enforcement agencies (e.g., Federal Bureau of Investigation).

\section{Treatment and Rehabilitation}

When asked if serial killers can be treated and rehabilitated, the vast majority of respondents felt that they could not be $(n=173,78.6 \%)$. A chi-square analysis detected a statistically significant finding regarding the ethnicity of respondents and their feelings about treatment and rehabilitation, $x^{2}(6, \mathrm{~N}=216)=12.75, \mathrm{p}=$ .047. Overall, $78.7 \%$ of the sample believe that serial killers cannot be treated or rehabilitated. Asian respondents were the least likely to feel that serial killers can be treated and rehabilitated $(85.7 \%)$, followed by White $(82.9 \%)$, and Black $(80.0 \%)$. Middle Eastern respondents were the most likely to feel that they can be treated and rehabilitated $(80.0 \%)$, followed by Multiracial respondents $(40.0 \%)$. Women $(22.7 \%)$ were slightly more likely to think that serial killers can be treated and rehabilitated than men (17.8\%), although this was not statistically significant. Lower class (15.8\%) respondents were the least likely to believe that serial killers could be treated and rehabilitated, whereas $18.3 \%$ of the working class and $25.8 \%$ of the middle class felt that they could be. None of the respondents 60 years of age and older believe that serial killers could be treated and rehabilitated. The rest of the age cohorts landed as such, 50's (14.3\%), 40's (8.3\%), 30's (22.0\%), and 20's (22.8\%). It appears that as people age they become more skeptical about whether or not serial killers can be effectively treated and rehabilitated.

\section{Death Penalty}

Of the total sample, $136(61.8 \%)$ of the respondents feel that serial killers should receive the death penalty. Men were more likely to feel this way $(68.1 \%)$ than women $(60.9 \%)$. Middle class respondents $(71.7 \%)$ were more likely to support the death penalty than lower class $(62.3 \%)$ and working class (59.4\%) respondents. In regard to ethnicity, White respondents $(70.6 \%)$ were the most likely to support the death penalty. This was followed up by Hispanic (64.5\%), Asian (64.3\%), and Black (63.6\%). None of the multiracial participants felt that the death penalty was a proper way to deal with a convicted serial killer. The single Native American respondent in the sample felt that these offenders should receive the death penalty. A one-way chi-square test produced significant findings regarding age cohorts and the death penalty, $x^{2}(5, N=214)=11.36, p=$ .045. All of the respondents in the study aged 60 years and older felt that serial killers should receive the death penalty. All of the respondents in their 40's also felt this way. Those in their 50's also leaned heavily in this direction (78.6\%). Respondents in their 30 's affirmed this at $61.0 \%$, while those in their 20's affirmed this at $59.0 \%$.

\section{Sadistic Personality}

Seventy-five percent of the total sample believe that serial murder is directly connected to a sadistic personality. Women in the study (76.6\%) were slightly more likely to think this than the men (72.6\%). Those in the middle class were the most likely to feel this way about serial killing and sadistic personalities (79.4\%), 
followed by working class (73.5), and lower class (68.4\%). Every respondent that identified as Middle Eastern, Multiracial, and Native American stated that they felt sadistic personality is connected to serial murder. Following this was Black $(90.9 \%)$, White

(74.3\%), Hispanic (72.4\%), and Asian (71.4\%). All of the participants 60 years of age and older felt that serial murder was connected to a sadistic personality. Those in their 40's felt this way $83.3 \%$ of the time. Those in their 30 's felt this way $78.0 \%$ of the time. This was followed by those in their 20 's $(74.5 \%)$ and those in their 50 's $(64.3 \%)$. Overall, it appears that the majority of respondents across each demographic studied believe that serial murder is connected to a sadistic personality.

\section{General Discussion}

The current study has strived to shed further light on the phenomenon of serial killing. There are a variety of theories and tentative etiologies that have been developed to try and better understand what drives a person to commit multiple acts of homicide. At this point in time, there have not been any validated explanations constructed to adequately capture the range of interacting factors and causes for serial murder (James, 2019; Lynes \& Wilson, 2015). The very nature of serial murder makes it a difficult subject to study beyond certain limited methods (Castle \& Hensley, 2002; LaBrode, 2007). Even with this being the case, serial murderers garner a sizable amount of academic and media attention (e.g., movies, television, journalistic). The motives behind serial murder are central focal points for legal investigations. The psychology behind serial killing fascinates academics, practitioners, and students in training. At the heart of all of this is the mass fascination with the heinous and reprehensible actions committed by these particular types of offenders.

There are common agreements among scholars concerning what often typifies the personality and psychological makeup of serial murders. Some of the most commonly recognized features and determinants include lack of guilt, lack of empathy, callousness, manipulation, conning, narcissism, lack of morality, impulsiveness, need for control/power (Fox \& DeLisi, 2019; Lachmann \& Lachmann, 2007; Reidy, Zeichner, \& Seibert, 2011). Other common traits and factors include high sensation seeking, affective shallowness, coldheartedness, hostile internal working models maladaptive patterns of attachment, charm, and affective disaffiliation (Anderson \& Marcus, 2019; Arrigo \& Griffin, 2004; Mokros, et al., 2010). Serial murder is believed to be the product of a destructive combination of neurological, psychological, cognitive, behavioral, and environmental factors (Miller, 2014; O'Toole, 2018).

The findings from this study show that there are clear patterns in the ways that people think about serial killers, why they kill, and what should be done with them once they are apprehended. Out of the 220 people that participated in this study, the majority of them believe that mental illness $(81.8 \%)$, abuse in childhood (80.5\%), and anger $(69.1 \%)$ are leading reasons that help to explain why serial murderers kill. Approximately 8 out of 10 participants believe that serial murder is directly connected to a sadistic personality. This would be in alignment with the general belief of the participants (8 out of 10 ) that serial killers cannot be effectively treated or rehabilitated. Sadism is widely believed to be a deeply embedded and harmful personality disposition (Haggar-Johnson \& Egan, 2010; Miller, 2014). Sadistic personality is a way of thinking, reacting, and behaving that is not readily treatable and that typically has low success rates in clinical settings. Sadipathic offenders are among the most difficult to effectively treat and rehabilitate.

Social stigma is a real problem for many people that are trying to manage and live with mental illnesses. Eight out of 10 respondents in this study believe that serial murder is directly associated with mental illness. It is not clear from this study which mental illnesses the respondents were thinking about, but it is 
important for mental health professionals and academics to work diligently to eliminate the various social stigmas that so often accompany misunderstood mental illnesses. The majority of respondents also felt that early childhood abuse was a key factor in the development of serial murder. It is well understood in therapeutic work that a person's early social experiences have a profound impact on their lifelong development and behaviors. Anger was also core factor identified by the study participants. Untreated anger can boil over at some point and unfortunately result in innocent people being victimized. These are both important examples highlighting why early intervention and treatment is so critical for helping young people that are suffering internally.

The findings from this study are also germane to the law, legal policy, and criminal justice. The majority of the participants in this study believe that serial killers should receive the death penalty $(62 \%)$. Seven out of 10 men feel that serial murderers should be put to death. Affirmative responses for the death penalty were also found across every satisfactorily represented racial/ethnic group, age cohort, and social class. Capital punishment is a topic that splits the nation. It would appear, when it comes to serial killers, that public sentiment may shift somewhat toward an affirmative standpoint. These tentative findings could have practical implications when it comes to matters concerning criminal trials, expert testimony, jury selection, and punishment. Psychologists and other mental health professionals should be well informed about what the public thinks about serial killers, their motives, their traits, their behaviors, and their culpability. Lawyers and judges connected to these particular types of criminal cases should be mindful and informed about these matters. Legal professionals involved in legislation and legal policy should also be well informed.

Future research could look further into any possible connections between serial murder, mental illness, childhood abuse, anger, and sadistic personality. Further research could also collect additional data from important demographic cohorts. This study was limited in this way concerning those from certain demographic groups (e.g., Native Americans, upper class). The findings from this study would also be enhanced by collecting more information from people living in other regions around the nation. For instance, those living in the southern states may have noticeably different views and beliefs when it comes to treatment and rehabilitation, mental illness, and the death penalty. With this, the findings from this study bring forth additional insight and information to help guide future academic, professional, and practical endeavors.

\section{Culminating Thoughts}

The core intention of this investigation was to further explore serial murder and the thoughts and beliefs of the general public regarding why serial killers commit their cold-blooded and remorseless acts. The intent was to also probe further into people's attitudes and beliefs about the death penalty, treatment and rehabilitation, and sadipathy. This study has shown that people generally have well established views and attitudes about serial killers, why they do what they do, and what should be done with them once they are apprehended. The findings from this study may be of use to professionals working across academic, mental health, and legal domains.

\section{References}

1. Anderson, A. E., \& Marcus, D. K. (2019). A bifactor model of meanness, cold- heartedness, callousness, and sadism. Personality and Individual Differences, 137, 192-197. doi: 10.1016/j.paid.2018.006

2. Arrigo, B. A., \& Griffin, A. (2004). Serial murder and the case of Aileen Wuornos: Attachment theory, psychopathy, and predatory aggression. Behavioral Sciences and the Law, 22, 375-393. doi: 10.1002/bsl.583

3. Bartels, R., \& Parsons, C. (2009). The social construction of a serial killer. Feminism \& Psychology, 19(2), 267-280. doi: 10/1177/0959353509102224 
4. Berger, R. (2019). Sadipathy - Conceptaulization and elucidation. American Journal of Psychiatric Research and Reviews, 2(7), 1-11. doi: 10.28933/ajprr-2019-06-1505

5. Castle, C., \& Hensley, C. (2002). Serial killers with military experience: Applying learning theory to serial murder. International Journal of Offender Therapy and Comparative Criminology, 46(4), 453-465. doi: 10.1177/0306624X02464007

6. DeLisi, M. (2018). Forensic epidemiology: Harnessing the power of public DNA sources to capture career criminals. Forensic Science International, 291, 20-21. doi: 10.1016/j.forsciint.2018.07.018

7. Fox, B., \& DeLisi, M. (2019). Psychopathic killers: A meta-analytic review of the psychopathyhomicide. Aggression and Violent Behavior, 44, 67-79. doi: 10.1016/j.av-b.2018.11.005

8. Garcia, D., \& Moraga, F. R. (2017). The dark cube: Dark character profiles and OCEAN. PeerJ, 5, 1-18. doi: 10. 7717 / peerj. 3845

9. Haggerty, K. D. (2009). Modern serial killers. Crime Media Culture, 5(2), 168-187. doi: 10.1177/1741659009335714

10. Haggar-Johnson, G., \& Egan, V. (2010). Sadistic personality disorder and sensational interests: What is the size and specificity of the association? The Journal of Forensic Psychiatry and Psychology, 21(1), 113-120 doi: $10.1080 / 14789940903174220$

11. Harmening, W. M. (2014). Serial killers: The psychosocial development of humanity's worst offender. The Journal of the American Academy of Psychiatry and the Law, 43(4), 541-542.

12. Holcombe, M. (2019). Confessed serial killer Samuel Little says he killed the woman in this sketch: Authorities hope the public knows who she is. CNN. Retrieved from www.cnn.com/2019/12/19/us/samuel-little-victim-sketch/mississippi//index.html

13. James, V. (2019). Denying the darkness: Exploring the discourses of neutralization of Bundy, Gacy, and Dahmer. Societies, 9(46), 1-17. doi: $10.3390 /$ soc 9020046

14. Janos, A. (2018). Samuel Little: What makes the elderly commit - and later confess to - murder? A \& E Television. Retrieved from www.aetv/realcrime/samuel-little-gold-state-killer-elderlycriminals-confessions

15. LaBrode, R. T. (2007). Etiology of the psychopathic serial killer: An analysis of antisocial personality disorder, psychopathy, and serial killer personality and crime scene characteristics. Brief Treatment and Crisis Intervention, 7(2), 151160. doi: 10.1093/brief-treatment/mhm004
16. Lachmann, A., \& Lachmann, F. M. (2007). The personification of evil: Motivations and fantasies of the serial killer. International Forum of Psychoanalysis, 4(1), 17-23. doi: 10.1080/08037065908409511

17. Lubaszka, C. K., Shon, P. C., \& Hinch, R. (2014). Healthcare serial killers as confidence men. Journal of Investigative Psychology and Offender Profiling, 11, 1-28. doi: 10.1002/jip.1394

18. Lynes, A., \& Wilson, D. (2015). Driving, pseudoreality and the BTK: A case study. Journal of Investigative Psychology and Offender Profiling, 12, 267-284. doi: 10.1002/jip.1441

19. March, E. (2019). Psychopathy, sadism, empathy, and the motivation to cause harm: New evidence confirms malevolent nature of the Internet troll. Personality and Individual Differences, 141, 133-137, doi: 10.1016/j.paid. 2019.01.001

20. Martens, W. H. (2011). Sadism linked to loneliness: Psychodynamic dimensions of the sadistic serial killer Jeffrey Dahmer. Psychoanalytic Review, 98(4), 493-514. doi: 10.1521/prev.2011.98.4.493

21. Miller, J. (2004). Monster? Portraits of a female "serial killer." PsycCRITIQUES, 49(7), doi: $10.1037 / 040086$

22. Miller, L. (2014). Serial killers: II. Development, dynamics, and forensics. Aggression and Violent Behavior, 19, 12-22. doi: 10.1016/j.avb.2013.11.003

23. Mokros, A., Osterheider, M., Hucker, S. J., \& Nitschke, J. (2010). Psychopathy and sexual sadism. Law \& Human Behavior, 35, 188-199. doi: 10.1007/s10979-010-9221-9

24. O'Toole, M. E. (2018). Understanding serial predatory behavior through the lens of the Golden State Killer. Violence and Gender, 5(2), 65-66. doi: 10.1089/vio.2018.29016.meo

25. Palazzolo, C. (2019). FBI seeking assistance connecting victims to Samuel Little's confessions. Federal Bureau of Investigation. Retrieved from www.fbi.gov/news/stories/samuel-little-mostprolific-serial-ki ller-in-us-history-100619

26. Ramsland, K. (2007). When women kill together. The Forensic Examiner, 64-66.

27. Reidy, D.E., Zeichner, A., \& Seibert, A. L. (2011). Unprovoked aggression: Effects of psychopathic traits and sadism. Journal of Personality, 79(1), 75-100. doi: 10.1111/j.146 7-6494.2010.00691.x

28. Sabalow, R. (2018). Just how heinous was he? Here's how the East Area Rapist tortured and terrorized victims. The Sacramento Bee. retrieved from www.sacbee.com/latest-news/ article209917839.html 
Raqota Berger, AJLLS, 2020 3:6

29. Spehr, A., Andreas, H., Habermann, N., Briken, P., \& Berner, W. (2010). Sexual murderers with adult or child victims: Are they different? Sexual Abuse: A Journal of Research and Treatment, 22(3), 290-314. doi: 10.1177/1079063210374346 